\title{
PHYSICAL INJURIES;
}

MAJOR CAUSE OF MEDICOLEGAL CASES REPORTED TO SERVICES HOSPITAL, LAHORE

1. MBBS, DMJ

Associate Professor

Forensic Medicine \& Toxicology

Department,

FMH College of Medicine and

Dentistry, Lahore.

2. MBBS, FCPS

Senior Registrar Surgical Unit III,

Services Hospital, Lahore.

Correspondence Address:

Dr. Mariam Arif

Forensic Medicine \& Toxicology

Department,

FMH College of Medicine and

Dentistry, Lahore.

kemc51@yahoo.com

Article received on:

27/05/2017

Accepted for publication:

$15 / 07 / 2017$

Received after proof reading:

03/11/2017

\begin{abstract}
Mariam Arif', Syed Hamad Rasool ${ }^{2}$
ABSTRACT... Introduction: Injury is one of the leading causes of mortality and morbidity worldwide. Objectives: The aim of the study was to determine the pattern of physical injuries in medicolegal cases presented to Services hospital, Lahore. Study Design: Descriptive study. Setting: Accident and emergency department of Services hospital, Lahore. Period: $1^{\text {st January }}$ 2014 and 31 ${ }^{\text {st}}$ December 2014. Method: All cases presenting for medico legal examination with physical injuries were included. Data was collected regarding age, gender, types of injuries, body area involved, causative weapon and whether certification of injuries was done according to Qisas and Diyat Ordinance. Results: A total of $86.4 \%$ cases were of physical injuries. Out of these cases, $73 \%$ of blunt weapon, $11 \%$ of firearm weapon, $10 \%$ of sharp weapon, $4 \%$ of road traffic accidents and $1.5 \%$ of bomb blast presented in the medico-legal clinic. Males (87.4\%) outnumbered females (12.5\%) Almost two-third of victims (64.2\%) were between 21 and 40 years of age. The head and neck were the areas most commonly injured in cases of blunt trauma $48.3 \%$ while limbs were more likely to be involved in other physical injuries. All cases were certified according to Qisas and Diyat Ordinance. Conclusion: It is the hour of need that both public and private sectors work together in devising and implementing effective injury prevention programs.
\end{abstract}

Key words: $\quad$ Physical Injuries, Blunt Trauma, Firearm Injuries, Qisas \& Diyat.

Article Citation: Arif M, Rasool SH. Physical injuries; Major cause of medicolegal cases reported to services hospital, Lahore. Professional Med J 2017;24(11):17271732. DOI:10.17957/TPMJ/17.4082

\section{INTRODUCTION}

According to $\mathrm{WHO}$, the standard definition of injury is injuries are caused by acute exposure to physical agents such as mechanical energy, heat, electricity, chemicals, or ionizing radiation interacting with the body in amounts or at rates that exceed the threshold of human tolerance. In some cases (for example, drowning and frostbite), injuries result from the sudden lack of essential agents such as oxygen or heat.1,2 Injury is one of the leading causes of mortality and morbidity worldwide. Globally injuries cause more than 5 million fatalities per year which is nearly 1.7 times the number of fatalities that result collectively from HIV, tuberculosis and malaria. ${ }^{3}$ This death toll is expected to rise to 8.4 million by year $2020 .^{2}$

Leading causes of injury related fatalities between 15-29 years are road traffic accidents, drowning, thermal injuries, poisoning and falls. ${ }^{1}$ Unfortunately, people with lower socioeconomic status are particularly vulnerable to injuries because of their unsafe working environment.

Deaths represent just a tip of iceberg of the injury burden. Huge number of people inflicted with non-fatal injuries is a challenging situation which costs a significant proportion of gross national product. ${ }^{1}$ National injury statistics in Australia, Netherlands, New Zealand, Sweden and USA indicate that minimum of 30 persons are hospitalized and 300are treated in emergency department for each mortality. ${ }^{1}$

On the other hand, the burden of injuries worldwide is disproportionately concentrated in low- and middle-income countries (LMIC) which account for $90 \%$ of the total burden of injuries with Southeast Asia and Western Pacific regions having the highest injury mortality worldwide. ${ }^{2,3}$ The national injury statistics of Pakistan reported that the annual incidence of injury was 41 injuries 
per 1000 persons with road traffic accidents as the predominant cause of injuries. ${ }^{1-3}$ Another major cause of injury is violence. ${ }^{1}$ Socioeconomic problems like population overgrowth and unemployment are the root cause of injuries inflicted as a result of violence.

A detailed medicolegal examination of the injuries is of paramount importance to find their nature, causative weapon and manner of infliction. This information can not only help the police to link the assailant with the crime but will also provide important statistical data for research purpose 4 . This will in turn help to develop and implement effective preventive measures at national level to reduce the burden of injuries.

\section{OBJECTIVES}

The aim of the study is:

1. To ascertain the pattern of physical injuries documented at accident and emergency department of Services Hospital, Lahore

2. To study the characteristics (age, gender) of the victims.

3. To know whether certification of injuries was being done according to Qisas \& Diyat Ordinance 4. To emphasize the need for developing preventive strategies at national level.

\section{MATERIAL AND METHODS}

This was a descriptive study conducted over a one year period from $1^{\text {st }}$ January, 2014 to $31^{\text {st }}$ December, 2014 at accident and emergency department of Services Hospital, Lahore. Individuals with physical injuries of all ages and gender who presented for medico-legal examination during the study period were included in the study. Cases of sexual assault, poisoning, alcohol and those with no medicolegal perspective or brought dead were excluded from study. A pre-tested structured proforma was used to collect the data regarding age, gender, types of injuries, body area involved, causative weapon and whether certification of injuries was done according to Qisas and Diyat Ordinance. Data was analyzed using SPSS 14. This study was approved by the ethical committee of Services Institute of Medical Sciences, Lahore.

\section{RESULTS}

Of the total 2166 medicolegal cases presented during the study period, $1872(86.4 \%)$ were of physical injuries. Maximum cases were from age group 21-30 years $772(41.23 \%)$ followed by $31-40$ years $430(22.97 \%)$. Least number of cases were seen in extremes of ages $0-10$ years $17(0.9 \%)$ and $>60$ years $(1.9 \%)$ as shown in Table-l.

\begin{tabular}{|l|c|c|c|c|c|}
\hline $\begin{array}{c}\text { Age } \\
\text { group (in } \\
\text { years) }\end{array}$ & \multicolumn{2}{|c|}{ Male } & \multicolumn{2}{c}{ Female } & \multirow{2}{*}{ Total (\%) } \\
\hline $0-10$ & 14 & 0.85 & 3 & 1.27 & $17(0.9)$ \\
\hline $11-20$ & 291 & 17.77 & 16 & 6.8 & $307(16.40)$ \\
\hline $21-30$ & 649 & 39.64 & 123 & 52.34 & $772(41.24)$ \\
\hline $31-40$ & 361 & 22.05 & 69 & 29.36 & $430(22.97)$ \\
\hline $41-50$ & 207 & 12.64 & 15 & 6.38 & $222(11.86)$ \\
\hline $51-60$ & 84 & 5.13 & 4 & 1.7 & $88(4.7)$ \\
\hline $61-70$ & 23 & 1.4 & 5 & 2.12 & $28(1.5)$ \\
\hline $71-80$ & 8 & 0.48 & 0 & 0 & $8(0.43)$ \\
\hline Total (\%) & 1637 & 87.44 & 235 & 12.55 & $1872(100)$ \\
\hline Table-I. Age and Gender wise distribution of Physical
\end{tabular}

Males (87.4\%) outnumbered females (12.5\%) as shown in Table-I and figure-1.

Of the total cases of physical injuries, almost three quarter of the victims suffered from blunt injuries (73\%) while firearm injuries 201(11\%) and sharp weapon injuries 191(10\%) were second and third commonest type of injuries noted. The least common were burns $4(0.2 \%)$ shown in Figure-1 and 2. Male preponderance was seen in all physical injuries except burns and bomb blast in which no female victim was reported (Figure-1). All injuries were certified according to Qisas and Diyat Ordinance.

The head and neck were the area's most commonly injured in cases of blunt trauma (48.3\%) while the upper and lower limbs were more likely to be involved in injuries from sharp weapons (46.1\%), firearm (66.2\%) and road traffic accidents $(70.44 \%)$ respectively as shown in Table-II. 


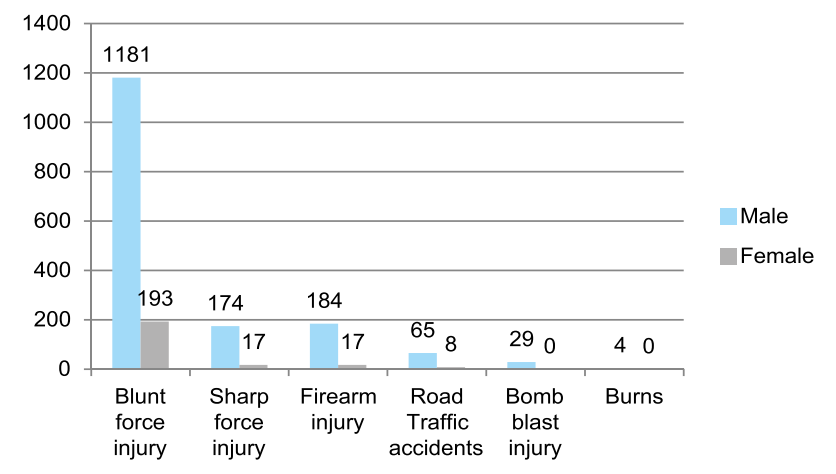

Figure-1. Categories of Physical Injuries
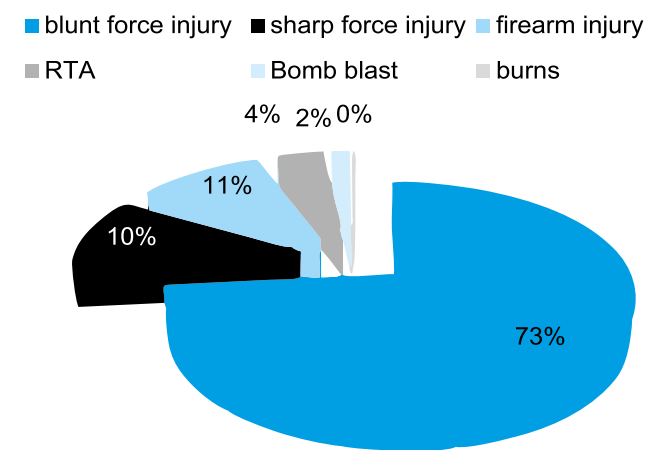

Fig 2. Physical Injuries

\begin{tabular}{|c|c|c|c|c|c|c|c|}
\hline $\begin{array}{l}\text { Body region } \\
\text { involved }\end{array}$ & $\begin{array}{l}\text { Blunt force } \\
\text { injury }\end{array}$ & $\begin{array}{c}\text { Sharp force } \\
\text { injury }\end{array}$ & $\begin{array}{c}\text { Firearm } \\
\text { injury }\end{array}$ & $\begin{array}{c}\text { Road Traffic } \\
\text { accidents }\end{array}$ & $\begin{array}{l}\text { Bomb blast } \\
\text { injuries }\end{array}$ & Burns & Total \\
\hline Head \& Neck & $\begin{array}{c}663 \\
(48.3)\end{array}$ & $\begin{array}{c}59 \\
(30.9)\end{array}$ & $\begin{array}{c}19 \\
(9.5)\end{array}$ & $\begin{array}{c}16 \\
(21.96)\end{array}$ & $\begin{array}{c}7 \\
(25)\end{array}$ & $\begin{array}{c}1 \\
(25)\end{array}$ & $\begin{array}{c}765 \\
(40.9)\end{array}$ \\
\hline Chest & $\begin{array}{c}144 \\
(10.5)\end{array}$ & $\begin{array}{c}27 \\
(14.1)\end{array}$ & $\begin{array}{c}23 \\
(11.4)\end{array}$ & $\begin{array}{c}4 \\
(6.06)\end{array}$ & $\begin{array}{c}2 \\
(5.35)\end{array}$ & $\begin{array}{c}2 \\
(50)\end{array}$ & $\begin{array}{c}202 \\
(10.8)\end{array}$ \\
\hline Abdomen & $\begin{array}{c}39 \\
(2.8)\end{array}$ & $\begin{array}{c}17 \\
(8.9)\end{array}$ & $\begin{array}{c}26 \\
(12.9)\end{array}$ & $\begin{array}{c}1 \\
(1.51)\end{array}$ & 0 & $\begin{array}{c}1 \\
(25)\end{array}$ & $\begin{array}{c}84 \\
(4.5)\end{array}$ \\
\hline Upper limb & $\begin{array}{c}356 \\
(25.9)\end{array}$ & $\begin{array}{c}72 \\
(37.7)\end{array}$ & $\begin{array}{c}35 \\
(17.4)\end{array}$ & $\begin{array}{c}19 \\
(25.75)\end{array}$ & $\begin{array}{c}9 \\
(30.35)\end{array}$ & 0 & $\begin{array}{c}491 \\
(26.2)\end{array}$ \\
\hline Lower limb & $\begin{array}{c}172 \\
(12.5)\end{array}$ & $\begin{array}{c}16 \\
(8.4)\end{array}$ & $\begin{array}{c}98 \\
(48.8)\end{array}$ & $\begin{array}{c}33 \\
(44.69)\end{array}$ & $\begin{array}{c}11 \\
(39.28)\end{array}$ & 0 & $\begin{array}{c}330 \\
(17.6)\end{array}$ \\
\hline Total & $\begin{array}{l}1374 \\
(73.4)\end{array}$ & $\begin{array}{c}191 \\
(10.2 \%)\end{array}$ & $\begin{array}{l}201 \\
(10.7)\end{array}$ & $\begin{array}{c}73 \\
(4 \%)\end{array}$ & $\begin{array}{c}29 \\
(1.5)\end{array}$ & $\begin{array}{c}4 \\
(0.2)\end{array}$ & $\begin{array}{l}1872 \\
(100)\end{array}$ \\
\hline
\end{tabular}

\section{DISCUSSION}

Of the total 2166 medicolegal cases presented during the study period, $1872(86.4 \%)$ were of physical injuries. Qudsia reported that physical trauma accounted for $91.6 \%$ of all cases which is comparable with our study. ${ }^{2}$ According to 2005 data from the Pakistan Health and Demographic Survey (PDS), injuries caused 42 deaths per 100,000 population or $6 \%$ of all deaths. ${ }^{3}$ Haridas found $84.1 \%$ cases of physical injuries also in line with our study. ${ }^{5}$ Several distal and proximal causative factors contributing to these injuries are poverty, unemployment, decreased tolerance, drug abuse, easy access to weapons and long delays in the delivery of justice to the perpetrators.

Our study showed that the most commonly affected age group was $21-30$ years (36\%) while the least number of cases were seen in $0-10$ years and above 60 years. This is consistent with studies from other cities of Pakistan ${ }^{2,6-8}$ and India. ${ }^{5,9}$ Greater involvement of youth is a challenging situation for developing country like ours as it causes a serious drain on the country's economy due to resultant long term/ permanent physical disability, psychological morbidity and cost of treatment.

During our study it was found that males (87.4\%) outnumbered females (12.6\%) as victims. Out of 213 cases, $182(85.45 \%)$ were males and 31 $(14.55 \%)$ werefemales in astudy from Gujranwala. ${ }^{6}$ Similar male preponderance has been reported in studies conducted in Abbottabad ${ }^{2}$, Lahore ${ }^{7}$ and Quetta. ${ }^{8}$ Also a study conducted at Kohlapur, India ${ }^{5}$ showed male victims to be $80 \%$. A study done in Dayton, Ohio, USA ${ }^{10}$ found the males to be affected in $70 \%$ cases. Majority of the victims were males in a study done in Turku, Finland. ${ }^{11}$ All these studies are in accordance with our findings.

Of the total cases of physical injuries, $73 \%$ were caused by blunt means which is in agreement with studies conducted in other cities of Pakistan. ${ }^{2,6-8}$ 
This finding is also in convergence with the study done in Patiala, India ${ }^{9}$ which found that blunt weapon was used as weapon of offence in $65 \%$ of cases of assault. Predominance of blunt trauma was also reported by a study done in Portugal. ${ }^{12}$

Firearm injuries accounted for $11 \%$ of cases in our study. A study from England and Wales reported that fire arm injuries were seen mainly in males accounting for $9 \%$ of the homicides and less than $5 \%$ of suicides. ${ }^{13}$ Firearm deaths comprised $12.5 \%$ and $12.6 \%$ of all injury deaths in Nigeria $^{13}$ and Italy ${ }^{14}$ respectively. All these studies support our findings.

In our study, sharp weapon injuries were $10 \%$. Amjad $^{6}$ and Tajammul ${ }^{7}$ each observed that sharp edged weapons were responsible for $10.80 \%$ of the injuries in Gujranwala and Lahore respectively. A two-year study from Hyderabad reported similar finding $(10 \%){ }^{15} \mathrm{~A}$ one year study from Abbottabad ${ }^{2}$ reported $7.9 \%$ cases of physical trauma due to sharp weapons. During the seven year period (1987 to 1994) in Sweden, 1315 people presented to the hospitals with stab wounds, which amounts to 2.1 injuries/100 000 population/year. ${ }^{16}$ Moreover, the rates of homicide by use of sharp force were 0.2 (France) and 1.1 (USA) per 100,000. ${ }^{17}$ All these studies are in agreement with our findings. Contrary to this, deaths due to stabbing phenomenon are on the rise in England and India. ${ }^{17}$ The official statistics for England and Wales indicate that the most common weapon used in homicide incidents was sharp edged weapon (29\%). ${ }^{17}$ This can be explained by the fact that in western world, youth become independent early and are thus being exposed to violence at an early age as compared to our society.

In the light of these observations it might be concluded that cultural norms of the society predisposes the choice of weapon. Factors like illiteracy rate, urbanization, easy availability of weapons, increase in terrorist activities and deteriorating law and order situation influence the choice of weapon. Furthermore, intention of the assailant is also an important detrimental factor. Where the intention is to kill, the weapon is a firearm, but where the intention is to injure, blunt and sharp weapons are more likely to be used.

Large number of people fell prey to road traffic accidents everyday on our roads. ${ }^{18}$ However, injuries incurred during road traffic accidents amount to $4 \%$ in our study. This is contrary to the other studies which reported higher incidence.,25-8 This may be due to under reporting of cases probably because of minor nature of injuries and mutual settlements between parties without involving law and order forces.

The frequency of blast injuries was found to be $1.5 \%$ in our study. Terrorism in Pakistan has claimed greater toll of human lives since the last decade. The number of bomb blast causalities rose from 164 in 2003 to 3318 in $2009 .{ }^{19} \mathrm{~A}$ total of 35,000 victims fell prey to this catastrophe from September 2001 to May 2011. ${ }^{19}$ According to the Government of Pakistan, the financial burden imposed by direct and indirect economic costs of terrorism from 2000-2010 amounts to $\$ 68$ billion. ${ }^{19}$

Head and neck was the most common region of the body affected (48.3\%) in blunt trauma. The findings are similar to those of study done in Abbottabad $^{2}$ which found head and neck was most commonly injured in cases of blunt trauma $53.8 \%$. A study done in USA ${ }^{10}$ also observed head and neck to be most frequently affected in 54\% of blunt force injuries. Studies from Patiala, India $(71 \%)^{9}$ reported similar predilection. Upper and lower limbs were more likely to be involved in injury from sharp weapons $46.1 \%$ and firearms $66.2 \%$ respectively. Out of 60 injured persons by sharp weapons, the limbs were involved in over half of cases 35 (58.3\%) in study from Abottabad $^{2}$ which is consistent with our study. On the contrary, in study from Sukkur ${ }^{20}$, the most vulnerable anatomical part involved was neck $30 \%$ while a study conducted at Karachi ${ }^{17}$, observed that the most common site of stabbing was abdomen (53.9\%). An epidemiological study of gunshot injuries in Sialkot ${ }^{21}$ showed that the majority of firearm injuries were sustained on the lower limbs (47.5\%) followed by upper limbs (17.7\%). Limbs were involved in $41.3 \%$ and $50 \%$ 
cases in studies from Lahore and Bahawalpur respectively. ${ }^{14}$ However, our findings are in contrast to other studies. A study in Dammam, Saudi Arabia argued that the commonest site of firearm injury was head (36.7\%). ${ }^{22}$ Abdomen was the most common target area in a study in Kanpur, India ${ }^{23}$ while it was chest in study from Peshawar. ${ }^{24}$ It can be said that where the motive is to injure the victim without causing death such as during armed robberies, the assailant tends to target less dangerous sites primarily the limbs. The high incidence of lower limbs injuries in road traffic accidents is not in line with other studies. A four year study from Multan ${ }^{18}$ reported that head was the most common site of injury. Qudsia ${ }^{2}$ found that upper limbs were the most affected area of body. This could be explained by the fact that majority of the victims were pedestrians in our study and lower limbs are most common part injured in them. An analysis ofthe global burden of musculoskeletal injuries found that the rates of extremity injuries from falls and road traffic ranged from 1,000 to 2,600 per 100,000 per year in lower and middle income countries thus in accordance with our study. ${ }^{3}$ Hyder reported that road traffic accidents mostly affect pedestrians, two-wheelers and young males ${ }^{3}$ also supporting our findings.

\section{CONCLUSION}

Physical injuries constitute $86.4 \%$ of medicolegal cases. Males between 21 to 40 years of age are most likely to be victims. The head and neck were the area's most commonly injured in cases of blunt trauma while limbs were more likely to be involved in other physical injuries. All injuries were certified according to Qisas and Diyat Ordinance.

Keeping in mind the cost-effectiveness of injury prevention programs and their success in other developing countries, it is the hour of need that both public and private sectors work together in devising and implementing effective injury prevention programs. Such programs should focus on increasing public awareness, improving hospital based trauma care at all levels, and strengthening data monitoring and research capacity to estimate the true burden of injuries. Copyright(C) 15 July, 2017.

\section{REFERENCES}

1. Nasrullah M. Xiang $H$. The Epidemic of Injuries in Pakistan- A neglected problem. J Pak Med Assoc 2008;420-1.

2. Hassan Q, Bashir MZ, Shah MM. Physical Trauma -A Leading Cause of Medico Legal Cases at DHQ Hospital Abbottabad. J Ayub Med Coll Abbottabad 2010; 22(2): 156-159.

3. Hyder AA, Razzak JA. The Challenges of Injuries and Trauma in Pakistan: An Opportunity for Concerted Action. Public Health. 2013; 127(8): 699-703. Available online at doi:10.1016/j.puhe.2012.12.020.

4. Hila A, Ekin NC, Gu"ImenMK, et al. Homicide in Adana, Turkey. A 5-Year Review. Am J Forensic Med and Patho2005; 26(2):141-145.

5. Haridas SV, Pawale DA. A Retrospective Study Of Pattern Of Clinical Medico-Legal Cases Registered At Tertiary Health Care Centre In Kolhapur District. Journal of Forensic Medicine, Science and Law 2104; 23(2):1-7.

6. Bhatti MA, Mahmood S, Hanif S. Profile of Medicolegal Cases Attending Trauma Center Of District Headquarter Teaching Hospital, Gujranwala. Esculapio 2013; 9(3):146-149.

7. Tajammul N, Chaudhary TH, Hanif H, Bhatti MA. Profile of Medicolegal Cases at Jinnah Hospital Lahore. Annals.2005; 2(3): 56-8.

8. Marri MZ, Baloch U. Frequency and Pattern of Medico Legal Cases Reported at Sandeman Civil Hospital Quetta Baluchistan-One Year Study. Medico-legal update $2011 ; 11(2)$ : 40-43.

9. Oberoi SS, Aggarwal KK, Bhullar DS, Aggarwal AD, Walia DS, Singh SP. Profile of Assault Cases in Patiala. J Punjab Acad Forensic Med Toxicol 2012; 12(1):17-21.

10. Murphy GK. 'Beaten to death'. An autopsy series of homicidal blunt force injuries. Am J Forensic Med Pathol. 1991; 12 (2): 98-101.

11. Wahlsten $P$, Koiranen $V$, Saukko $P$. Survey of medicolegal investigation of homicides in the city of Turku, Finland. J Clin Forensic Med. 2007; 14:243-252.

12. Coelho L, Ribeiro T, Dias R, Santos A, Magalhaes T. Elder homicide in north of Portugal. J Forensic Leg Med. 2010; 17:383- 387.

13. MirzaFH, Hassan Q, Naz R et al. Spectrum of Medicolegal Deaths in Metropolis of Karachi: An Autopsy Based Study. Pak Journal of Medicine and Dentistry 2013; 2(4):4-9. 
14. Arif M, Rasool SH, Maqsood M. Morbidity and Mortality of Firearm Injury at a Tertiary Care Hospital in Lahore. JFJMC 2013; 7(4): 40-45.

15. Yousfani GM, Memon MU. Spectrum of unnatural deaths in Hyderabad an autopsy based study. Journal of Dow University Health Sciences Karachi 2010; 4(2):54-57.

16. BostromL. Trends in the Incidence and Severity of Stab Wounds in Sweden 1987-1994. European J Sur 2000; 166(10)765-770 doi: 10.3109/110241500447380.

17. Mirza FH, Hasan Q, Memon AA, Adil SE. Audit of sharp weapon deaths in Metropolis of Karachi- An Autopsy based study. J Ayub Med Coll Abbottabad 2010; 22(4): 66-9.

18. Arif M, Ahmed M, Rasool SH. Road Traffic AccidentsAutopsy Based study in Multan. TPMJ 2015;22(5):621626.

19. Terrorism in Pakistan- Wikipedia https:// en.m.wikipedia.org $>$ Terrorism in Pakistan-
Wikipedia.

20. Memon A, Kazi MA, Shaikh W. Incidence of Homicidal Injuries by Sharp Force Trauma at Sukkur. J LiaquatUni Med Health Sci. 2015; 14(01):03-5.

21. Hussain S, Shirwany TAK, Hakam I. Epidemiology of gunshot injuries in district Sialkot. Jszmc 2013; 4(4); 504-508.

22. Al Madni O, Kharosha M, Shotar A. Firearm fatalities in Dammam, Saudi Arabia. Med Sci Law 2008; 48(3):237240.

23. Sachan R, Kumar A, Verma A. Frequency of Firearm Injuries, Deaths and Related Factors in Kanpur, India; an Original Study with Review of Literature. International Journal of Medical Toxicology and Forensic Medicine. 2013; 3(3): 88-95.

24. Zaffar M, Bashir Z. Homicide death due to rifled firearm injury in Peshawar, Pakistan. JCSP 2010; 20(2); 87-89.

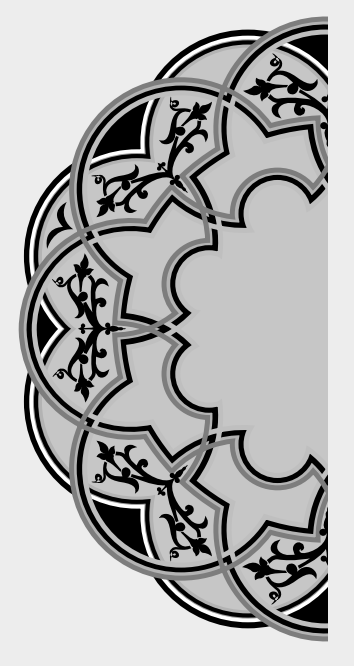

\title{
"Do not look where you fell, but where you slipped."
}

\author{
Unknown
}

\section{AUTHORSHIP AND CONTRIBUTION DECLARATION}

\begin{tabular}{|c|l|l|}
\hline Sr. \# & \multicolumn{1}{|c|}{ Author-s Full Name } & \multicolumn{1}{c|}{ Contribution to the paper } \\
\hline 1 & Mariam Arif & $\begin{array}{l}\text { Prepared the proposal in } \\
\text { consultation with other } \\
\text { authors, data collection and } \\
\text { compilation, wrote major } \\
\text { portion of the manuscript. } \\
\text { Data collection and } \\
\text { compilation manuscript } \\
\text { writing. } \\
\text { All the authors read and } \\
\text { approved the final manuscript. }\end{array}$ \\
\hline \multirow{2}{*}{ Syed Hamad Rasool } & \\
&
\end{tabular}

